\title{
Effects of the Plane of Nutrition on Physicochemical Characteristics and Sensory Quality Traits of the Muscle in Finishing Pigs
}

\author{
Chai Hyun Lee ${ }^{1}$, Dae-Yun Jung ${ }^{1}$, Jung Seok Choi ${ }^{2}$, Sang-Keun $\mathrm{Jin}^{1}$, and Chul Young Lee* \\ Regional Animal Industry Center, Gyeongnam National University of Science and Technology, Jinju 660-758, Korea \\ ${ }^{1}$ Department of Animal Resources Technology, Gyeongnam National University of Science and Technology, \\ Jinju 660-758, Korea \\ ${ }^{2}$ Swine Science and Technology Center, Gyeongnam National University of Science and Technology, \\ Jinju 660-758, Korea
}

\begin{abstract}
This study was performed to examine the feasibility of using the low plane of nutrition (LPN) as a means of improving the meat quality of crossbred finishing pigs with a medium weight gain potential. Twenty-four barrows and 24 gilts weighing approximately $48 \mathrm{~kg}$ were placed on LPN [a finisher $(2.86 \mathrm{Mcal} \mathrm{ME} / \mathrm{kg}$ and $0.67 \%$ lysine $)$ for $91 \mathrm{~d}$ ] or on a high plane of nutrition [HPN; a commercial grower for $38 \mathrm{~d}$ and a finisher (3.35 Mcal ME/ $\mathrm{kg}$ and $0.9 \%$ lysine) for $46 \mathrm{~d}$ ]. Five barrows and five gilts per treatment weighing approximately $125 \mathrm{~kg}$ were slaughtered after the indicated days on the respective diets, followed by physicochemical analysis and sensory evaluation on their muscles. Overall average daily gain was $12.6 \%$ less in the LPN group vs. the HPN group $(p<0.05)$. The redness $\left(\mathrm{a}^{*}\right)$ of fresh longissimus muscle (LM) from the loin as well as from Boston butt was greater in the LPN group vs. HPN whereas the shear force for fresh LM from these primals and semimembranosus muscle was lower in the former. In sensory evaluation for cooked LM, no treatment effect was detected in any of the quality traits examined, except for a lower color score in the LPN vs. HPN group. Results suggest that meat quality of the finishing pigs can be improved to some extent by using LPN. However, the present pigs, whose backfat thickness was $24 \mathrm{~mm}$ at $125 \mathrm{~kg}$, are thought not to be lean enough to be fattened over $120 \mathrm{~kg}$.
\end{abstract}

Keywords: finishing pig, plane of nutrition, physicochemical characteristics, meat quality, sensory evaluation

\section{Introduction}

Growth rate and body composition as well as physicochemical characteristics and sensory quality traits of the muscles of finishing pigs are determined by genetics, sex, nutrition, slaughter weight, and others (Ellis et al., 1996; Pettigrew and Esnaola, 2001; Schinckel et al., 2012; Sutton et al., 1997). Pig breeding has been aimed primarily at increasing the litter size and lean/weight gain as well as decreasing fat deposition represented by backfat thickness and thereby increasing the production efficiency, especially feed efficiency. This has often resulted in a decrease in some meat quality traits including water-holding capacity and marbling (Huff-Lonergan et al., 2003; Sonesson et al., 1998; van Wijk et al., 2005). Given the

*Corresponding author: Chul Young Lee, Regional Animal Industry Center, Gyeongnam National University of Science and Technology, Jinju 660-758, Korea Tel: +82-55-751-3285, Fax: +82-55-753-4422, E-mail: cylee@gntech.ac.kr genetic background, the rate of weight gain as well as backfat thickness, which is greater in barrows than in gilts, increases with the increasing plane of nutrition or dietary energy density (Correa et al., 2006; de Lange et al., 2001; Lee et al., 2002).

Jeong et al. (2010) have analyzed the relationships of the meat quality traits to the dietary energy density and slaughter weight between $110 \mathrm{~kg}$ and $135 \mathrm{~kg}$ in pigs with a high lean gain potential using pooled data from previous studies of Lee et al. $(2006,2007)$ and Park et al. (2007, 2009a, 2009b). Following are the main results of their analysis. The redness [CIE (1986) $\mathrm{a}^{*}$ ] and subjective marbling and overall acceptability scores for fresh loin were positively correlated with the slaughter weight. In addition, the $\mathrm{a}^{*}$ value of fresh loin also increased when the animals were fed a low-energy diet containing 3.0 Mcal DE/kg vs. a control diet (3.2 Mcal DE/kg). Overall scores of the sensory quality traits for fresh and cooked loin, Boston butt and ham increased slightly between $110-$ and $125-\mathrm{kg}$ live weights, and did not change signifi- 
cantly between 125 and $135 \mathrm{~kg}$. In contrast to this, in finishing pigs with a low weight/lean gain potential, physiochemical characteristics and sensory quality scores including the redness and marbling of fresh and cooked loin were not influenced by the dietary energy density between 3.0 and $3.4 \mathrm{Mcal} \mathrm{DE} / \mathrm{kg}$ in the study of $\mathrm{Ha}$ et al. (2010). On the other hand, it could not be determined in that study whether or not meat quality could be improved by using the low-energy diet and thereby increasing the slaughter weight to $125 \mathrm{~kg}$ or greater, because the pigs were almost over-fat at approximately $115 \mathrm{~kg}$ of body weight, the average slaughter weight in Korea in recent years (KPPA, 2014), and therefore were slaughtered at that weight. As such, effects of the dietary energy density on meat quality of medium-lean finishing pigs slaughtered at a high body weight are unknown. The present study was therefore performed to investigate the feasibility of improving the pork quality by using the low plane of nutrition and thereby slaughtering at a high body weight in finishing pigs with a medium weight gain potential. To this end, the medium-lean pigs used in the present study were slaughtered at $125 \mathrm{~kg}$ of predetermined weight, which was the median between 135 and $115 \mathrm{~kg}$ of subjectively assessed maximum slaughter weights for the aforementioned high- and low-lean pigs, respectively, based on their carcass and meat quality after the finishing phase on the medium-energy diet (3.2 Mcal DE/kg).

\section{Materials and Methods}

\section{Animals}

The experimental protocol for this study conformed to the guideline of Institutional Animal Care and Use Committee (IACUC) at Gyeongnam National University of Science and Technology. The animals used in the present study were handled humanely and also did not receive any prolonged constraint throughout the experiment.

Out of a number of pens of 108-d-old (YorkshirexLandrace) $\times$ Duroc pigs with a medium weight gain potential, 2 barrow pens and 2 gilt pens were chosen arbitrarily and 12 animals weighing approximately $48 \mathrm{~kg}$ were selected out of 17 animals in each of the four selected pens. The present experiment was performed under a $2(\operatorname{sex}) \times 2$ (plane of nutrition; 'high' vs. 'low') arrangement of treatments in which each 24 selected animals consisting of equal numbers of barrows and gilts in two respective pens received a low-plane finisher diet containing $2.86 \mathrm{Mcal}$ $\mathrm{ME} / \mathrm{kg}$ for $91 \mathrm{~d}$ or a commercial grower for $38 \mathrm{~d}$ followed by a high-plane finisher ( $3.35 \mathrm{Mcal} \mathrm{ME} / \mathrm{kg}$ ) for $46 \mathrm{~d}$
Table 1. Composition of the diets of varying planes of nutrition used in the present study (as-fed basis)

\begin{tabular}{cccc}
\hline \hline \multirow{2}{*}{ Component } & \multirow{2}{*}{ Grower $^{1)}$} & \multicolumn{2}{c}{ Finisher $^{2)}$} \\
\cline { 3 - 4 } & & Low & High \\
\hline Crude protein (\%) & 16.6 & 13.0 & 16.5 \\
Lysine (\%) & 1.0 & 0.67 & 0.90 \\
Crude fat (\%) & 5.0 & 2.93 & 7.19 \\
DE (Mcal $/ \mathrm{kg})$ & 3.45 & 3.06 & 3.60 \\
ME (Mcal $/ \mathrm{kg})$ & - & 2.86 & 3.35 \\
\hline
\end{tabular}

${ }^{1)}$ Commercial diets; declared minimum.

${ }^{2)}$ Corn-wheat-soybean meal-based diets manufactured for the present experiment; calculated composition.

(Table 1). The high- and low-plane finishers were formulated to meet the nutrients densities including the lysine concentration suggested by NSNG (2010) and NRC (2012) for finishing pigs with high and low lean gain potentials, respectively.

Body weight was measured on d 0,38, and 69 of the experiment in all animals and on d 84 and 91, the last days on feed for the high-plane and low-plane groups, respectively. Five barrows and five gilts per treatment weighing approximately $125 \mathrm{~kg}$ were fasted overnight following the measurement of their final weights, after which the animals were transported to a local abattoir for $40 \mathrm{~min}$ and slaughtered after a 3-h lairage. Feed intake was not measured, partly because the present feeding trial was performed on a commercial farm using a mechanical feeder system, partly because only selected animals in each pen were used as experimental units.

\section{Physicochemical analysis of the muscle}

After the measurement or evaluation of the weight, backfat thickness, and others on the hot carcass by the grading official (MAFRA, 2014), the carcass was chilled for $24 \mathrm{~h}$ at $2 \pm 2^{\circ} \mathrm{C}$ and fabricated according to the standard of MFAS (2013). The loin comprising the longissimus muscle (LM) widely used as the representative muscle for physicochemical analysis and sensory evaluation (Judge et al., 1989) as well as a second representative lean primal ham was removed from the carcass. In addition, Boston butt containing the upper part of the LM, which contains more intramuscular fat than the LM of the loin (Clausen and Ovesen, 2001; Kang et al., 2011), was also taken as another type of muscle for its higher fat content. The loin, Boston butt, and ham were transported to the laboratory and the LM and semimembranosus muscle (SM) were removed from the former two primals and ham, respectively, for physicochemical analysis and sensory evaluation on the muscle described below. 
Physicochemical characteristics of the fresh and cooked muscles were determined basically as described previously (Jin et al., 2004; Lee et al., 2002). Briefly, the color of fresh muscle and backfat was measured by the CIE (1986) L* (lightness), $a^{*}$ (redness) and $b^{*}$ (yellowness) standards using a chromameter (CR-40, Minolta Co., Japan) calibrated to the white plate $\left(\mathrm{L}^{*}=93.5 ; \mathrm{a}^{*}=0.3132\right.$; $\mathrm{b}^{*}=0.3198$ ). The $\mathrm{pH}$ was measured on a homogenate of the muscle in a 9 volume of distilled water (w/v). Drip loss was determined by measuring the weight loss of a 2$\mathrm{cm}$ muscle slice during 24-h suspension at $4^{\circ} \mathrm{C}$ in a polypropylene bag. The shear force was measured using Instron 3343 (US/MX50, A\&D Co., USA) on a 9.5 mm-diametral muscle core which had been prepared by longitudinally probing the muscle, with the chart speed, maximum load, and measure speed set at 120/min, $10 \mathrm{~kg}$, and $60 \mathrm{~mm} / \mathrm{min}$, respectively. Textural properties of cooked muscle were measured after heating a muscle sample cut to a 4-cm thickness and a 6-cm length in a water bath at $80^{\circ} \mathrm{C}$ for $1 \mathrm{~h}$ and cooling it at $4^{\circ} \mathrm{C}$ for $2 \mathrm{~h}$ in a polypropylene bag. Cooking loss was defined by the difference in muscle weights before and after the heating and cooling; firmness and chewiness were measured on the cross-section of the cooked muscle sliced to a 2-cm height; shear force was measured as in fresh muscle.

Contents of moisture, protein and fat of the muscle were determined by the oven-drying, Kjeldahl and Soxhlet extraction methods, respectively, according to the AOAC (2007) procedures. Composition of fatty acids was determined by gas chromatography using the AT - Silar capillary column (Alltech, USA) after extraction of total lipids by the method of Folch et al. (1957), with operation conditions set at $230^{\circ} \mathrm{C}$ of initial temperature (T), $250^{\circ} \mathrm{C}$ of injector $\mathrm{T}, 240^{\circ} \mathrm{C}$ of detector $\mathrm{T}, 2^{\circ} \mathrm{C} / \mathrm{min}$ of programming rate, $50 \mathrm{~mL} / \mathrm{min}$ of flow rate, and 100:1 of split ratio.

\section{Sensory evaluation}

Sensory quality traits of the LM of fresh loin and Boston butt and the SM of the ham were evaluated according to the 9-notch whole-number point scale (Jin et al., 2004; Park et al., 2007, Park et al., 2009a) by six panelists trained in the meat science lab of the present workers as described by Meilgaard et al. (1991). Fresh meat was given the arbitrary point 1 to 9 for each of its quality attributes ranging from "very poor meat color; undetectable marbling; severe off-odor; severe dripping, and very poor overall acceptability" to "superb meat color; superb marbling; no off-odor; little dripping; and superb overall acceptability." As for cooked muscle, only the LM of the loin, which is widely used as the representative muscle for this purpose (Bredahl et al., 1998), was cooked and evaluated by the analogous criteria for color, aroma, taste, juiciness, tenderness, and overall palatability. To be brief, each sensory attribute was scored in such a way that a greater point indicates a better quality.

\section{Statistical analysis}

All data were analyzed by the General Linear Model procedure included in the SAS (2008) statistical software package. The statistical model included sex, plane of nutrition, and an interaction of them, as well as the panelist in sensory evaluation, as fixed errors, with individual animal defined as the error term (experimental unit). Effects of the treatment, sex, and their interaction with $p \leq 0.05$ were judged as significant. Means were compared using the PDIFF option only when the $p$-value for the fixed error or the interaction of the fixed errors was 0.05 or less.

\section{Results}

\section{Growth performance}

Body weights of the animals on $\mathrm{d} 0$ and 38 of the experiment and average daily gain (ADG) during the initial $38 \mathrm{~d}$ did not differ between the animals placed on the low plane of nutrition (LPN) and those on the high plane of nutrition (HPN) or between barrows and gilts (Table 2). However, ADG during d 38-69 and 69-84 (for HPN) or -91 (for LPN) were greater in the HPN group than in the LPN group ( $p<0.05$ and $p<0.01$, respectively). Overall ADG also was greater in the HPN vs. LPN group (897 g vs. $785 \mathrm{~g} ; \mathrm{SE}=19 \mathrm{~g} ; p<0.01)$. However, neither of the effects for the sex and sex $\times$ treatment interaction on ADG was significant during any period of the experiment.

\section{Physicochemical characteristics of the muscle}

Of those animals whose muscles were used for physicochemical analysis and sensory evaluation, the HPN group had a greater live weight and a greater carcass weight than the LPN group, although the live and carcass weights were within $125 \pm 2.5 \mathrm{~kg}$ and $96.0 \pm 2.5 \mathrm{~kg}$, respectively, in all of the four experimental groups (Table 3). Dressing percentage and backfat thickness, however, did not differ between the HPN and LPN groups or between the barrow and gilt groups.

The $\mathrm{L}^{*}$ value of the LM from the loin did not differ between the HPN and LPN groups or between barrows and gilts. The $\mathrm{a}^{*}$ value of the loin LM was greater in the 
Table 2. Effects of the plane of nutrition on growth of finishing pigs

\begin{tabular}{|c|c|c|c|c|c|c|c|c|}
\hline \multirow{2}{*}{ Variable } & \multicolumn{2}{|c|}{ Low plane ${ }^{\text {I) }}$} & \multicolumn{2}{|c|}{ High plane $^{2)}$} & \multirow{2}{*}{ SEM } & \multicolumn{3}{|c|}{$P P$-value } \\
\hline & $\mathrm{B}^{3)}$ & $\mathrm{G}^{3)}$ & $\mathrm{B}^{3)}$ & $\mathrm{G}^{3)}$ & & $\mathrm{N}^{4)}$ & $\mathrm{S}^{4)}$ & $\mathrm{N} \times \mathrm{S}$ \\
\hline \multicolumn{9}{|l|}{ Body wt (kg) } \\
\hline Day 0 & 48.6 & 45.6 & 48.7 & 49.0 & 1.7 & 0.31 & 0.44 & 0.34 \\
\hline Day 38 & 82.5 & 80.6 & 82.9 & 82.6 & 1.4 & 0.37 & 0.45 & 0.54 \\
\hline Day 69 & 106.2 & 104.4 & 111.1 & 108.5 & 1.9 & 0.02 & 0.24 & 0.84 \\
\hline Day 84/91 & 120.5 & 115.0 & 125.0 & 122.9 & 2.3 & 0.01 & 0.11 & 0.49 \\
\hline \multicolumn{9}{|l|}{ ADG (g) } \\
\hline Day $0-38$ & 892 & 923 & 899 & 885 & 36 & 0.67 & 0.81 & 0.53 \\
\hline Day 38-69 & 807 & 785 & 912 & 834 & 32 & 0.02 & 0.12 & 0.39 \\
\hline Day 69-84/91 & 649 & 482 & 956 & 957 & 67 & $<0.01$ & 0.22 & 0.21 \\
\hline Overall & 797 & 771 & 915 & 879 & 27 & $<0.01$ & 0.26 & 0.86 \\
\hline
\end{tabular}

${ }^{15}$ Fed the low-plane finisher (Table 1) throughout the experiment (d 0-91).

${ }^{2)}$ Fed the grower and high-plane finisher during d 0-38 and 38-84, respectively.

${ }^{3)} \mathrm{B}$, barrow; G, gilt. Data are means of 12 animals.

${ }^{4)} \mathrm{N}$, plane of nutrition; $\mathrm{S}$, sex.

Table 3. Physicochemical characteristics of the longissimus dorsi muscles of finishing pigs which were placed on either the low or high plane of nutrition

\begin{tabular}{|c|c|c|c|c|c|c|c|c|}
\hline \multirow{2}{*}{ Variable } & \multicolumn{2}{|c|}{ Low plane ${ }^{1)}$} & \multicolumn{2}{|c|}{ High plane $^{2)}$} & \multirow{2}{*}{ SEM } & \multicolumn{3}{|c|}{$P$-value } \\
\hline & $\mathrm{B}^{3)}$ & $\mathrm{G}^{3)}$ & $\mathrm{B}^{3)}$ & $\mathrm{G}^{3)}$ & & $\mathrm{N}^{4)}$ & $\mathrm{S}^{4)}$ & $\mathrm{N} \times \mathrm{S}$ \\
\hline Live wt (kg) & 124.1 & 122.9 & 127.3 & 125.5 & 1.3 & 0.04 & 0.28 & 0.80 \\
\hline Carcass wt (kg) & 96.6 & 94.2 & 98.4 & 98.2 & 1.4 & 0.05 & 0.35 & 0.43 \\
\hline Dressing (\%) & 77.9 & 76.6 & 77.3 & 78.3 & 0.7 & 0.45 & 0.83 & 0.12 \\
\hline $\mathrm{BFT}^{4,5)}(\mathrm{mm})$ & 26.0 & 22.0 & 24.5 & 24.9 & 1.8 & 0.71 & 0.32 & 0.23 \\
\hline & \multicolumn{8}{|c|}{ Fresh muscle } \\
\hline \multicolumn{9}{|l|}{ Color } \\
\hline CIE L* (muscle) & 59.2 & 55.4 & 56.1 & 54.5 & 1.5 & 0.20 & 0.09 & 0.47 \\
\hline CIE a* (muscle) & 9.37 & 9.64 & 8.18 & 7.84 & 0.60 & 0.02 & 0.95 & 0.62 \\
\hline CIE b* (backfat) & 3.47 & 3.94 & 4.49 & 4.43 & 0.26 & 0.01 & 0.44 & 0.33 \\
\hline $\mathrm{pHu}$ & 5.83 & 5.73 & 5.68 & 5.70 & 0.04 & 0.04 & 0.26 & 0.16 \\
\hline Drip loss (\%) & 4.81 & 6.27 & 7.28 & 6.11 & 0.62 & 0.08 & 0.82 & 0.05 \\
\hline Shear force $\left(\mathrm{kg} / \mathrm{cm}^{2}\right)$ & 3.29 & 3.17 & 5.74 & 5.62 & 0.50 & $<0.01$ & 0.81 & 1.00 \\
\hline Moisture (\%) & 73.1 & 74.2 & 73.5 & 74.3 & 0.2 & 0.28 & $<0.01$ & 0.60 \\
\hline Crude protein $(\%)$ & 22.83 & 22.12 & 22.99 & 22.57 & 0.44 & 0.49 & 0.21 & 0.75 \\
\hline Crude fat (\%) & 1.97 & 1.45 & 1.73 & 1.42 & 0.21 & 0.54 & 0.07 & 0.65 \\
\hline & \multicolumn{8}{|c|}{ Composition of fatty acids (\%) } \\
\hline $18: 0$ & 13.79 & 13.59 & 13.21 & 13.08 & 0.45 & 0.24 & 0.72 & 0.93 \\
\hline $18: 1$ & 44.53 & 45.24 & 44.36 & 44.01 & 0.80 & 0.40 & 0.82 & 0.52 \\
\hline $18: 2$ & 6.38 & 7.89 & 8.08 & 9.12 & 0.76 & 0.07 & 0.11 & 0.76 \\
\hline $20: 4$ & 1.17 & 1.76 & 1.44 & 1.69 & 0.26 & 0.69 & 0.12 & 0.52 \\
\hline $\mathrm{SFA}^{4)}$ & 42.85 & 40.63 & 41.34 & 40.63 & 0.81 & 0.36 & 0.09 & 0.36 \\
\hline PUFA $^{4)}$ & 8.54 & 10.82 & 10.63 & 11.92 & 1.02 & 0.14 & 0.10 & 0.63 \\
\hline \multirow[t]{2}{*}{$\mathrm{n}-3$} & 0.91 & 1.08 & 1.01 & 1.00 & 0.04 & 0.88 & 0.05 & 0.04 \\
\hline & \multicolumn{8}{|c|}{ Cooked muscle } \\
\hline Cooking loss $(\%)$ & 42.9 & 43.5 & 42.6 & 43.2 & 0.7 & 0.72 & 0.44 & 0.99 \\
\hline Shear force $\left(\mathrm{kg} / \mathrm{cm}^{2}\right)$ & 4.91 & 5.81 & 5.04 & 4.77 & 0.47 & 0.34 & 0.50 & 0.23 \\
\hline Firmness $\left(\mathrm{kg} / \mathrm{cm}^{2}\right)$ & 1.63 & 1.87 & 1.39 & 1.72 & 0.15 & 0.21 & 0.08 & 0.76 \\
\hline Chewiness (kg) & 1.09 & 0.98 & 0.63 & 0.89 & 0.21 & 0.21 & 0.71 & 0.40 \\
\hline
\end{tabular}

${ }^{1)}$ Fed the low-plane finisher (Table 1) throughout the experiment (d 0-91).

${ }^{2)}$ Fed the grower and high-plane finisher during $\mathrm{d}$ 0-38 and 38-84, respectively.

${ }^{3)} \mathrm{B}$, barrow; G, gilt; Final Data are means of 5 animals.

${ }^{4)} \mathrm{N}$, plane of nutrition; S, sex; BFT, backfat thickness; SFA, saturated fatty acids; PUFA, polyunsaturated fatty acids.

${ }^{5)}$ Average of the measurements between the 11 and $12^{\text {th }}$ ribs and at the last rib adjusted for a $125-\mathrm{kg}$ live weight. 
LPN group than in the HPN group (9.50 vs. 8.01) whereas the $b^{*}$ value of backfat covering the LM was greater in the latter. The pHu was greater in the LPN vs. HPN group, but the $\mathrm{pH}$ values of both groups were within the normal range of 5.0-6.0 of the RFN (reddish-pink, firm, and nonexudative) pork (Warner et al., 1997). Drip loss, which was not influenced by the treatment or sex, was greater in gilts vs. barrows on the LPN, but not on HPN. The shear force for the LM was less in the LPN group than in the HPN group ( 3.23 vs. $5.68 \mathrm{~kg} / \mathrm{cm}^{2}$ ). Regarding the sex effect, none of the physicochemical characteristics described so far differed between gilts and barrows.

The content of moisture in the loin LM was greater in gilts than in the barrows whereas protein and fat contents of the muscle did not differ between the sexes. However, none of moisture, protein and fat contents differed between the treatments. In composition of fatty acids, none of the percentages of stearic acid (18:0), oleic acid (18:1), linoleic acid (18:2), and arachidonic acid (20:4) differed between the treatments or sexes. The ratios of total saturated fatty acids, polyunsaturated fatty acids, and n-3 fatty acids also were not influenced by the treatment or sex, except for a greater percentage of n-3 fatty acids in the gilt vs. barrow on the LPN, but not on HPN. In cooked LM, none of cooking loss, shear force, firmness, and chewiness was affected by the treatment or sex.

In fresh LM from Boston butt, the $\mathrm{L}^{*}$ value as well as drip loss did not differ between the treatments or sexes (Table 4). The $\mathrm{a}^{*}$ value and $\mathrm{pHu}$ of this $\mathrm{LM}$ were greater in the LPN vs. HPN group as in fresh loin LM, whereas shear force was less in the former $(p<0.01)$. The fat content of this muscle did not differ between the treatments or sexes. In fresh SM, the LPN group exhibited a greater $\mathrm{L}^{*}$ value than the HPN group [48.7 vs. $\left.45.0(p<0.01)\right]$. The $\mathrm{a}^{*}$ value, $\mathrm{pHu}$, and drip loss of the SM were not affected by the treatment or sex. Shear force for the SM, as in the LM, was less in the LPN vs. HPN group whereas fat content was greater in the HPN vs. LPN group (1.44 vs. $1.01 \% ; p<0.05)$.

\section{Sensory evaluation of meat quality}

None of the color, marbling, off-odor, drip, and overall acceptability scores for fresh loin LM differed between the LPN and HPN groups or between barrows and gilts, except for a greater acceptability score for the barrow vs. gilt on the LPN, but not on HPN (Table 5). In fresh LM from Boston butt, the off-odor score was greater in the LPN vs. HPN group, otherwise, neither of the treatment and sex effects was detected in any other sensory quality trait. The fresh SM of the LPN group exhibited greater marbling and off-odor scores than the HPN group, but color, drip and overall acceptability scores for this muscle were not influenced by the treatment or sex. In sensory evaluation for cooked loin LM, the color score was

Table 4. Physicochemical characteristics of the muscle of the fresh ham and Boston butt in finishing pigs which were placed on either the low or high plane of nutrition

\begin{tabular}{|c|c|c|c|c|c|c|c|c|}
\hline \multirow{2}{*}{ Variable } & \multicolumn{2}{|c|}{ Low plane ${ }^{1)}$} & \multicolumn{2}{|c|}{ High plane $^{2)}$} & \multirow{2}{*}{ SEM } & \multicolumn{3}{|c|}{$P$ P-value } \\
\hline & $\mathrm{B}^{3)}$ & $\mathrm{G}^{3)}$ & $\mathrm{B}^{3)}$ & $\mathrm{G}^{3)}$ & & $\mathrm{N}^{4)}$ & $\mathrm{S}^{4)}$ & $\mathrm{N} \times \mathrm{S}$ \\
\hline & \multicolumn{8}{|c|}{ Longissimus muscle from Boston butt } \\
\hline \multicolumn{9}{|l|}{ Color } \\
\hline CIE L* & 49.4 & 49.0 & 49.5 & 47.7 & 1.2 & 0.64 & 0.36 & 0.56 \\
\hline CIE a* & 20.6 & 22.1 & 19.1 & 18.3 & 0.8 & $<0.01$ & 0.70 & 0.19 \\
\hline $\mathrm{pHu}$ & 6.16 & 6.25 & 5.70 & 5.83 & 0.09 & $<0.01$ & 0.27 & 0.82 \\
\hline Drip loss (\%) & 1.03 & 0.97 & 0.70 & 1.28 & 0.32 & 0.97 & 0.44 & 0.34 \\
\hline Shear force $\left(\mathrm{kg} / \mathrm{cm}^{2}\right)$ & 1.95 & 2.77 & 4.51 & 4.05 & 0.38 & $<0.01$ & 0.64 & 0.11 \\
\hline Crude fat $(\%)$ & 3.43 & 2.32 & 4.29 & 3.48 & 0.61 & 0.12 & 0.14 & 0.81 \\
\hline & \multicolumn{8}{|c|}{ Semimembranosus muscle of the ham } \\
\hline \multicolumn{9}{|l|}{ Color } \\
\hline CIE L* & 47.9 & 49.6 & 45.3 & 44.6 & 1.3 & $<0.01$ & 0.70 & 0.35 \\
\hline CIE a* & 15.12 & 13.54 & 12.64 & 13.80 & 0.72 & 0.14 & 0.77 & 0.07 \\
\hline $\mathrm{pHu}$ & 6.20 & 6.21 & 6.00 & 5.96 & 0.11 & 0.06 & 0.86 & 0.85 \\
\hline Drip loss (\%) & 1.19 & 1.17 & 0.87 & 1.21 & 0.17 & 0.43 & 0.34 & 0.30 \\
\hline Shear force $\left(\mathrm{kg} / \mathrm{cm}^{2}\right)$ & 2.92 & 3.09 & 5.56 & 5.88 & 0.38 & $<0.01$ & 0.53 & 0.85 \\
\hline Crude fat $(\%)$ & 1.14 & 0.88 & 1.48 & 1.40 & 0.15 & 0.02 & 0.28 & 0.55 \\
\hline
\end{tabular}

${ }^{1)}$ Fed the low-plane finisher (Table 1) throughout the experiment (d 0-91).

${ }^{2)}$ Fed the grower and high-plane finisher during $\mathrm{d}$ 0-38 and 38-84, respectively.

${ }^{3)} \mathrm{B}$, barrow; G, gilt. Data are means of 5 animals.

${ }^{4)} \mathrm{N}$, plane of nutrition; S, sex. 
Table 5. Sensory meat quality traits of finishing pigs which were placed on either the low or high plane of nutrition ${ }^{1)}$

\begin{tabular}{|c|c|c|c|c|c|c|c|c|}
\hline \multirow{2}{*}{ Variable } & \multicolumn{2}{|c|}{ Low plane ${ }^{21}$} & \multicolumn{2}{|c|}{ High plane $^{31}$} & \multirow{2}{*}{ SEM } & \multicolumn{3}{|c|}{$P$-value } \\
\hline & $\mathrm{B}^{4)}$ & $\mathrm{G}^{4)}$ & $\mathrm{B}^{4)}$ & $\mathrm{G}^{4)}$ & & $\mathrm{N}^{5)}$ & $\mathrm{S}^{5)}$ & $\mathrm{N} \times \mathrm{S}$ \\
\hline & \multicolumn{8}{|c|}{ Fresh longissimus muscle from the loin } \\
\hline Color & 7.78 & 7.50 & 7.18 & 7.35 & 0.21 & 0.09 & 0.78 & 0.30 \\
\hline Marbling & 8.02 & 7.38 & 7.40 & 7.65 & 0.21 & 0.42 & 0.38 & 0.05 \\
\hline Off-odor & 8.00 & 7.97 & 7.85 & 7.97 & 0.04 & 0.08 & 0.32 & 0.08 \\
\hline Drip & 7.65 & 7.33 & 7.62 & 7.78 & 0.24 & 0.40 & 0.76 & 0.33 \\
\hline \multirow[t]{2}{*}{ Acceptability } & 7.97 & 7.52 & 7.40 & 7.68 & 0.15 & 0.20 & 0.58 & 0.03 \\
\hline & \multicolumn{8}{|c|}{ Fresh longissimus muscle from Boston butt } \\
\hline Color & 8.27 & 7.83 & 7.88 & 7.82 & 0.16 & 0.24 & 0.14 & 0.27 \\
\hline Marbling & 8.08 & 7.87 & 7.92 & 7.67 & 0.19 & 0.35 & 0.23 & 0.93 \\
\hline Off-odor & 8.08 & 8.08 & 7.92 & 7.93 & 0.05 & 0.01 & 0.87 & 0.87 \\
\hline Drip & 8.35 & 7.97 & 7.82 & 7.68 & 0.23 & 0.09 & 0.27 & 0.59 \\
\hline \multirow[t]{2}{*}{ Acceptability } & 8.08 & 7.90 & 7.83 & 7.68 & 0.17 & 0.18 & 0.33 & 0.92 \\
\hline & \multicolumn{8}{|c|}{ Fresh semimembranosus muscle of the ham } \\
\hline Color & 7.90 & 7.33 & 7.70 & 7.73 & 0.16 & 0.54 & 0.11 & 0.08 \\
\hline Marbling & 7.90 & 7.52 & 7.32 & 7.18 & 0.17 & 0.01 & 0.14 & 0.46 \\
\hline Off-odor & 8.03 & 7.97 & 7.87 & 7.78 & 0.07 & 0.03 & 0.31 & 0.91 \\
\hline Drip & 7.90 & 7.48 & 7.73 & 7.77 & 0.15 & 0.70 & 0.21 & 0.15 \\
\hline \multirow[t]{2}{*}{ Acceptability } & 7.87 & 7.45 & 7.63 & 7.65 & 0.14 & 0.91 & 0.18 & 0.15 \\
\hline & \multicolumn{8}{|c|}{ Cooked longissimus muscle from the loin } \\
\hline Color & 7.57 & 7.65 & 8.13 & 8.00 & 0.19 & 0.03 & 0.90 & 0.57 \\
\hline Aroma & 7.38 & 7.63 & 7.23 & 7.37 & 0.15 & 0.20 & 0.23 & 0.71 \\
\hline Taste & 7.35 & 7.70 & 7.35 & 7.48 & 0.16 & 0.50 & 0.14 & 0.50 \\
\hline Juiciness & 7.28 & 7.27 & 7.18 & 7.53 & 0.11 & 0.48 & 0.17 & 0.13 \\
\hline Tenderness & 7.70 & 7.28 & 7.30 & 7.33 & 0.15 & 0.27 & 0.23 & 0.16 \\
\hline Palatability & 7.40 & 7.62 & 7.38 & 7.58 & 0.17 & 0.89 & 0.24 & 0.96 \\
\hline
\end{tabular}

${ }^{1)}$ Evaluated by six panelists according to an arbitrary 1-to-9 whole-number point scale. A greater score indicates a greater quality in all quality traits. A greater score in off-flavor or drip therefore indicates a lesser extent of the corresponding trait.

${ }^{2)} \mathrm{Fed}$ the low-plane finisher (Table 1) throughout the experiment (d 0-91).

${ }^{3)}$ Fed the grower and high-plane finisher during $\mathrm{d}$ 0-38 and 38-84, respectively.

${ }^{4)} \mathrm{B}$, barrow; G, gilt; Data are means of 5 animals.

${ }^{5)} \mathrm{N}$, plane of nutrition; $\mathrm{S}$, sex.

greater in the HPN vs. LPN group. However, neither the treatment nor sex exhibited any significant effect on aroma, taste, juiciness, tenderness, or palatability.

\section{Discussion}

The use of LPN for the finishing pigs resulted in a $12.6 \%$ decrease in $\mathrm{ADG}$ without significantly influencing backfat thickness when compared with growth performance of the pigs placed on HPN. These results for LPN were similar to the effects for the low-energy diet in finishing pigs observed in previous studies (Ha et al., 2012; Lee et al., 2002; Park et al., 2009a).

Notably, the pigs placed on LPN exhibited higher $\mathrm{pHu}$ values in the loin and Boston butt LM than those on HPN. The pHu is known to increase when post-mortem glycolysis is insufficient due to a low muscular glycogen store at slaughter resulting from glycogenolysis-inducing pre-slaughter stresses, a low availability of dietary carbohydrates prior to slaughter, or others (Bee et al., 2006; Huff-Lonergan et al., 2003). In this context, it is tempting to speculate that a lower ratio of the carbohydrate-rich grains in the LPN vs. HPN diet $(58.7 \%$ vs. $70.1 \%$; data not shown), as well as a reduced anabolic status in the LPN vs. HPN group as indicated by a much lower ADG in the former during $\mathrm{d}$ 69-84/91, could have resulted in a lesser muscular glycogen store in the former. It is not known, however, whether or not the high $\mathrm{pH}$ greater than 6.0, a known cause of DFD (dark, firm, and dry) pork (Warner et al., 1997), due to LPN exerted any negative effect on the meat quality of the Boston butt LM and SM, although LPN did not cause a decrease in either the L* value below 42 typical of DFD or in the score for any of the quality traits including the color in sensory evaluation on the muscles.

The increased redness $\left(a^{*}\right)$ of fresh LM from both the 
loin and Boston butt in response to LPN vs. HPN, which was consistent with the effect for the low-energy diet on this attribute in finishing pigs (Park et al., 2009a), is thought to be a positive effect of LPN on meat quality, in that a redder color is perceived as better quality by consumers. The redness of the muscle is known to increase with the increase in its myoglobin content due to an increased slaughter age or $\mathrm{Fe}^{2+}: \mathrm{Fe}^{3+}$ ratio of the prosthetic heme group within the myoglobin molecule following an increased muscular pH (Park, 2004). The increased redness of the LM in the LPN group vs. HPN is thus at least partly attributable to the 7-d older age at the time of slaughter and the higher $\mathrm{pHu}$ in the former.

The reduced shear force in the LPN vs. HPN group in all the fresh muscles examined is also thought to be a positive effect of the former on the quality of fresh meat. Moreover, the greater off-odor score in the LPN vs. HPN group in sensory evaluation for the fresh Boston butt LM and SM added to the beneficial effects of LPN on meat quality. On the other hand, the effect of LPN on the meat quality trait associated with intra-muscular fat was inconclusive, in that the greater fat content in the HPN vs. LPN group and the greater marbling score in the latter were contradictory to each other in the SM whereas in the loin and Boston butt LM, neither fat content nor marbling score was influenced by the plane of nutrition.

Collectively, the present results suggest that use of LPN for finishing pigs is effective for improving the quality of their meat to some extent when they are slaughtered at approximately $125 \mathrm{~kg}$ of body weight irrespective of the maximum allowance of carcass weight for the $1^{+}$carcass grade by the current grading standard [92.5 kg $(121.7 \mathrm{~kg}$ of live weight at a dressing percentage of $76 \%$ ); MAFRA, 2014]. This was consistent with the conclusion as to the effect of the low-energy diet containing $3,000 \mathrm{kcal} \mathrm{DE} / \mathrm{kg}$ in finishing pigs in Park et al. (2009a). However, neither LPN nor the low dietary energy density (Park et al., 2009a) had any significant effect on overall quality of cooked meat evaluated by the sensory panel, although the color score was reduced by LPN in cooked LM in the present study. The positive changes in physicochemical and sensory quality attributes of fresh meat due to either dietary treatment therefore do not seem to be significant enough to influence the quality of cooked meat.

Apart from meat quality, the backfat thickness (BFT) adjusted for a $125-\mathrm{kg}$ live weight of the pigs raised on LPN was $24.0 \mathrm{~mm}$, which is thought to be too high and also too close to $24.5 \mathrm{~mm}$ of the maximum allowance for the $1^{+}$-grade carcass (MAFRA, 2014). This is much grea- ter than $21.4 \mathrm{~mm}$ of BFT at the same live weight in the low-energy diet-fed high-lean pigs (Park et al., 2009a), in which the retrospectively assessed optimum slaughter weight for superior carcass and meat quality is $128 \pm 5 \mathrm{~kg}$ on the criteria that the optimum BFT is $22 \pm 1 \mathrm{~mm}$ (Park, 2011; Park et al., 2013a; MAFRA, 2014) and that the BFT increases at a rate of 0.20 to $0.25 \mathrm{~mm} / \mathrm{kg}$ live weight (Jeong et al., 2010; Park and Lee, 2011; Park et al., 2013b). If the same criteria are adopted for the present pigs endowed with a medium lean gain potential, the optimum slaughter weight is assessed to be $116 \pm 4 \mathrm{~kg}$. It remains unknown, though, whether or not the meat quality of the pigs will be improved by LPN when they are slaughtered at the predicted optimum weight.

\section{Acknowledgements}

This study was supported by grants from Taewon Farm, Gyeongnam National University of Science and Technology (GnTech), and the Regional Animal Industry Center at GnTech.

\section{References}

1. AOAC (2007) Official methods of analysis. 18th ed. Association of Official Analytical Chemists, Washington, D.C.

2. Bee, G., Biolley, C., Guex, G., Herzog, W., Lonergan, S. M., and Huff-Lonergan, E. (2006) Effects of available dietary carbohydrate and preslaughter treatment on glycolytic potential, protein degradation, and quality traits of pig muscles. $J$. Anim. Sci. 84, 191-203.

3. Bredahl, L., Grunert, K. G., and Fertin, C. (1998) Relating consumer perceptions of pork quality to physical product characteristics. Food Qual. Prefer. 9, 273-281.

4. CIE (1986) Colorimetry. 2nd ed. CIE Publication No. 15.2, Commision Internationale de l'Eclairage, Vienna.

5. Clausen, I. and Ovesen, L. (2001) Proximate contents, losses and gains of fat, protein and water comparing raw, hospitaland household-cooked pork cuts. J. Food Compost. Anal. 14, 491-503.

6. Correa, J. A., Faucitano, L., Laforest, J. P., Rivest, J., Marcoux, M., and Gariepy, C. (2006) Effects of slaughter weight on carcass composition and meat quality in pigs of two different growth rates. Meat Sci. 72, 91-99.

7. de Lange, C. F. M., Birkett, S. H., and Morel, P. C. H. (2001) Protein, fat, and bone tissue growth in swine. In: Swine nutrition. 2nd ed. Lewis, A. J. and Southern, L. L. (eds), CRC Press, New York, pp. 65-82.

8. Ellis, M., Webb, A. J., Avery, P. J., and Brown, I. (1996) The influence of terminal sire genotype, sex, slaughter weight, feeding regime and slaughter-house on growth performance and carcass and meat quality in pigs and on the organoleptic properties of fresh pork. Anim. Sci. 62, 521-530. 
9. Folch, J., Lees, M., and Sloane-Stanley, G. H. S. (1957) A simple method for the- isolation and purification of total lipids from animal tissue. J. Biol. Chem. 226, 497-500.

10. Ha, D. M., Kim, G. D., Han, J. C., Jeong, J. Y., Park, M. J., Park, B. C., Joo, S. T., and Lee, C. Y. (2010) Effects of dietary energy level on growth efficiency and carcass quality traits of finishing pigs. J. Anim. Sci. Technol. 52, 191-198.

11. Ha, D. M., Park, B. C., Park, M. J., Song, Y. M., Jin, S. K., Park, J. H., and Lee, C. Y. (2012) Effects of plane of nutrition on growth performance and meat quality traits in finishing pigs. J. Anim. Sci. Technol. 54, 449-454.

12. Huff-Lonergan, E., Lonergan, S. M., and Beerman, D. H. (2003) Animal growth and meat quality. In: Biology of growth of domestic animals. Scanes, C. G. (ed). Iowa State Press, Ames, IA, USA, pp. 220-232.

13. Jeong, J. Y., Park, B. C., Ha, D. M., Park, M. J., Joo, S. T., and Lee, C. Y. (2010) Effects of increasing slaughter weight on production efficiency and carcass quality of finishing gilts and barrows. Korean J. Food Sci. An. 30, 206-215.

14. Jin, S. K., Kim, I. S., Hur, S. J., Hah, K. H., and Kim, B. W. (2004) Effects of feeding period on carcass and objective meat quality in crossbred longissimus muscle. J. Anim. Sci. Technol. 46, 811-820.

15. Judge M. D., Aberle, E. D., Forrest, J. C., Hedrick, B. H., and Merkel, R. A. (1989) Meat grading and evaluation. In: Principles of meat science. Kendall/Hunt Publishing Company, Dubuque, IA, USA, pp. 311-333.

16. Kang, H. S., Seo, K. S., Kim, K. T., and Nam, K. C. (2011) Comparison of pork quality characteristics of different parts from domesticated pig species. Korean J. Food Sci. An. 31, 921-927.

17. KPPA (2014) Korea Pork Producers Association. Statistics.

18. Lee, C. Y., Kim, M. H., Ha, D. M., Park, J. W., Oh, G. Y., Lee, J. R., Ha, Y. J., and Pak, B. C. (2007) Effects of the energy level of the finisher diet on growth efficiency and carcass traits of 'high'-market weight pigs. J. Anim. Sci. Technol. 49, 471-480.

19. Lee, C. Y., Kwon, O. C., Ha, D. M., Shin, H. W., Lee, J. R., Ha, Y. J., Lee, J. H., Ha, S. H., Kim, W. K., Kim, K. W., and Kim, D. H. (2006) Growth efficiency, carcass quality characteristics and profitability of finishing pigs slaughtered at 130 vs. 110 kg. J. Anim. Sci. Technol. 48, 493-502.

20. Lee, C. Y., Lee, H. P., Jeong, J. H., Baik, K. H., Jin, S. K., Lee, J. H., and Sohn, S. H. (2002) Effects of restricted feeding, low-energy diet, and implantation of trenbolone acetate plus estradiol on growth, carcass traits, and circulating concentrations of insulin-like growth factor (IGF)-I and IGF-binding protein-3 in finishing barrows. J. Anim. Sci. 80, 84-93.

21. MAFRA (2014) Grading standards for livestock products (in Korean). Notification No. 2014-4 of the Ministry of Agriculture, Food and Rural Affairs, Republic of Korea.

22. Meilgaard, M., Civille, G. V., and Carr, B. T. (1991). Sensory evaluation techniques. 3rd ed. CRC Press, New York, USA, pp. 211-222.

23. MFAS (2013) Definition of the primal cuts and grades of the carcasses of farm animals (in Korean). Notification No. 2013153 of the Ministry of Food and Drug Safety, Republic of
Korea.

24. NRC (2012) Nutrient Requirements of Swine. 11th ed. National Academy Press, Washington, D.C., USA.

25. NSNG (2010) National swine nutrition guide. U.S. Pork Center of Excellence (USPCE), Iowa State University, Ames, IA, USA.

26. Park, B. C. (2011) Opinions regarding the increase of pig slaughter weight. $10^{\text {th }}$ Symposium of the Korean Pig Industry Research Society "Strategies for Increasing Pork Supply through an Increase of the Market Weight," Jul. 13, 2011, Proceedings pp. 81-82.

27. Park, B. C. and Lee, C. Y. (2011) Feasibility of increasing the slaughter weight of finishing pigs. J. Anim. Sci. Technol. 53, 211-222.

28. Park, G. B. (2004). Meat science. Sun Jin Mun Hwa Sa, sdoul, Korea, pp. 185-224.

29. Park, B. C., Ha, D. M., Park, M. J., Jin, S. K., Park J. H., and Lee, C. Y. (2013a) Effects of the decreased carcass grade of finishing pigs due to increasing market weight on carcass quality traits and physicochemical and sensory quality characteristics of the loin and belly. J. Anim. Sci. Technol. 55, 203-210.

30. Park, M. J., Ha, D. M., Shin, H. W., Lee, S. H., Kim, W. K., Ha, S. H., Yang, H. S., Jeong, J. Y., Joo, S. T., and Lee, C. Y. (2007) Growth efficiency, carcass quality characteristics and profitability of 'high'-market weight pigs. J. Anim. Sci. Technol. 49, 459-470.

31. Park, M. J., Jeong, J. Y., Ha, D. M., Han, J. C., Sim, T. G., Park, B. C., Park, G. B., Joo, S. T., and Lee, C. Y. (2009a) Effects of dietary energy level and slaughter weight on growth performance and grades and quality traits of the carcass in finishing pigs. J. Anim. Sci. Technol. 51, 143-154.

32. Park, M. J., Jeong, J. Y., Ha, D. M., Park, J. W., Sim T. G., Yang, H. S., Lee, C. Y., Joo, S. T., and Pak, B. C. (2009b) Relationships of the slaughter weight to growth performance and meat quality traits in finishing pigs fed a low-energy diet. J. Anim. Sci. Technol. 51, 135-142.

33. Park, M. J., Park, B. C., Ha, D. M., Kim, J. B., Jang, K. S., Lee, D. H., Kim, G. T., Jin, S. K., and Lee, C. Y. (2013b) Effects of increasing market weight of finishing pigs on backfat thickness, incidence of the 'caky-fatty' belly, carcass grade, and carcass quality traits. J. Anim. Sci. Technol. 55, 195-202.

34. Pettigrew, J. E. and Esnaola, M. A. (2001) Swine nutrition and pork quality: a review. J. Anim. Sci. 79(E. Suppl.), E316-E342.

35. SAS (2008) SAS/STAT Software for PC. Release 9.2. SAS Institute Inc., Cary, NC, USA.

36. Schinckel, A. P., Einstein, M. E., Jungst, S., Matthews, J. O., Fields, B., Booher, C., Dreadin, T., Fralick, C., Tabor, S., Sosnicki, A., Wilson, E., and Boyd, R. D. (2012) The impact of feeding diets of high or low energy concentration on carcass measurements and weight of primal and subprimal lean cuts. Asian-Austral. J. Anim. Sci. 25, 531-540.

37. Sonesson, A. K., de Greef, K. H., and Meuwissen, T. H. E. (1998) Genetic parameters and trends of meat quality, carcass composition and performance traits in two selected lines of large white pigs. Livest. Prod. Sci. 57, 23-32.

38. Sutton, D. S., Ellis, M., Lan, Y., McKeith, F. K., and Wilson, 
E. R. (1997) Influence of slaughter weight and stress gene genotype on the water-holding capacity and protein gel characteristics of three porcine muscles. Meat Sci. 46, 173-180.

39. van Wijk, H. J., Arts, D. J. G., Matthews, J. O., Webster, M., Ducro, B. J., and Knol, E. F. (2005) Genetic parameters for carcass composition and pork quality estimated in a commer- cial production chain. J. Anim. Sci. 83, 324-333.

40. Warner, R. D., Kauffman, R. G., and Greaser, M. L. (1997) Muscle protein changes post mortem in relation to pork quality traits. Meat Sci. 45, 339-352.

(Received 2014.5.7/Revised 2014.7.28/Accepted 2014.7.28) 